Article

\title{
How Do Aerosol Properties Affect the Temporal Variation of MODIS AOD Bias in Eastern China?
}

\author{
Minghui Tao ${ }^{1}$, Zifeng Wang ${ }^{1, *}$, Jinhua Tao ${ }^{1, *}$, Liangfu Chen ${ }^{1}$, Jun Wang ${ }^{2}{ }^{(D)}$, Can Hou ${ }^{1}$, \\ Lunche Wang ${ }^{3}$, Xiaoguang $\mathrm{Xu}^{2}$ and Hao $\mathrm{Zhu}^{1}$ \\ 1 State Key Laboratory of Remote Sensing Science, Institute of Remote Sensing and Digital Earth, \\ Chinese Academy of Sciences, Beijing 100101, China; taomh@radi.ac.cn (M.T.); chenlf@radi.ac.cn (L.C.); \\ wumagua@163.com (C.H.); zhuhao453271826@163.com (H.Z.) \\ 2 Department of Chemical and Biochemical Engineering, Center of Global and Regional Environmental Research, \\ University of Iowa, Iowa City, IA 52242, USA; jun-wang-1@uiowa.edu (J.W.); xiaoguang-xu@uiowa.edu (X.X.) \\ 3 Laboratory of Critical Zone Evolution, School of Earth Sciences, China University of Geosciences, \\ Wuhan 430074, China; wang@cug.edu.cn \\ * $\quad$ Correspondence: wangzf@radia.ac.cn (Z.W.); taojh@radi.ac.cn (J.T.); Tel.: +86-010-6488-9567 (Z.W. \& J.T.)
}

Academic Editors: Yang Liu and Omar Torres

Received: 21 June 2017; Accepted: 1 August 2017; Published: 3 August 2017

\begin{abstract}
The rapid changes of aerosol sources in eastern China during recent decades could bring considerable uncertainties for satellite retrieval algorithms that assume little spatiotemporal variation in aerosol single scattering properties (such as single scattering albedo (SSA) and the size distribution for fine-mode and coarse mode aerosols) in East Asia. Here, using ground-based observations in six AERONET sites, we characterize typical aerosol optical properties (including their spatiotemporal variation) in eastern China, and evaluate their impacts on Moderate Resolution Imaging Spectroradiometer (MODIS) Collection 6 aerosol retrieval bias. Both the SSA and fine-mode particle sizes increase from northern to southern China in winter, reflecting the effect of relative humidity on particle size. The SSA is $\sim 0.95$ in summer regardless of the AEROENT stations in eastern China, but decreases to 0.85 in polluted winter in northern China. The dominance of larger and highly scattering fine-mode particles in summer also leads to the weakest phase function in the backscattering direction. By focusing on the analysis of high aerosol optical depth (AOD) $(>0.4)$ conditions, we find that the overestimation of the AOD in Dark Target (DT) retrieval is prevalent throughout the whole year, with the bias decreasing from northern China, characterized by a mixture of fine and coarse (dust) particles, to southern China, which is dominated by fine particles. In contrast, Deep Blue (DB) retrieval tends to overestimate the AOD only in fall and winter, and underestimates it in spring and summer. While the retrievals from both the DT and DB algorithms show a reasonable estimation of the fine-mode fraction of AOD, the retrieval bias cannot be attributed to the bias in the prescribed SSA alone, and is more due to the bias in the prescribed scattering phase function (or aerosol size distribution) in both algorithms. In addition, a large yearly change in aerosol single scattering properties leads to correspondingly obvious variations in the time series of MODIS AOD bias. Our results reveal that the aerosol single scattering properties in the MODIS algorithm are insufficient to describe a large variation of aerosol properties in eastern China (especially change of particle size), and can be further improved by using newer AERONET data.
\end{abstract}

Keywords: aerosol; MODIS; retrieval bias; eastern China; AERONET

\section{Introduction}

Atmospheric aerosols play a vital role in regional climate by redistributing solar radiation in the Earth-atmosphere system and modifying cloud properties [1]. Furthermore, fine particles 
near the surface can cause air pollution, which has robust relation with epidemic diseases affecting human health [2]. Unlike long-lived greenhouse gases such as $\mathrm{CO}_{2}$, the amount and properties of aerosol particles vary largely over space and time due to diverse emission sources and short lifetime, which make it a challenge to quantify the magnitude of aerosols and their climate effects [3]. Since the 1990s, a ground-based remote sensing network has been established to explore aerosol optical and microphysical properties [4]. Meanwhile, a variety of sophisticated sensors, such as Moderate Resolution Imaging Spectroradiometer (MODIS), Multi-angle Imaging SpectroRadiometer (MISR), Ozone Monitoring Instrument (OMI), CALIPSO, and other sensors have been launched to obtain aerosol information with global coverage [5-8].

Aerosol optical properties, including aerosol optical depth (AOD) and aerosol single scattering properties (single scattering albedo (SSA) and phase function) regulate the role of aerosols in radiative transfer calculations; these properties in turn change with mass, size, shape, and the composition of the particles [9]. Since satellite spectral radiances at the top of the atmosphere (TOA) are affected by the radiative interactions between surface reflectance and aerosol scattering, not all aerosol properties can be fully constrained and retrieved reliably from satellite measurements at the TOA. Hence, aerosol single scattering properties (such as SSA and size distribution for fine or coarse particles that affect phase function) are often derived from a cluster analysis of ground observations, and are subsequently used in the algorithms for the satellite remote sensing of aerosols. For example, the MODIS aerosol algorithm only retrieves the AOD and the fraction between fine-mode and coarse mode AODs $[10,11]$, while aerosol single scattering properties are fixed with only consideration of seasonal and continental-scale variation.

The aerosol properties in eastern China are characterized by large spatiotemporal variations [12,13], which are not considered in the MODIS retrieval algorithm, and hence the impact of such variations on MODIS AOD biases deserve a dedicated investigation. Widespread haze pollution usually occurs over eastern China, with the mixing of anthropogenic emissions, natural dust, and biomass burning smoke $[14,15]$. Ground observations show a distinct temporal variation and area-dependent change of optical and microphysical properties of aerosol particles [16-19], which resonates with our recent evaluation of MODIS Collection (C) 6 aerosol retrievals in China that show considerable bias with obvious geographic difference and temporal trend [20]. However, previous ground-based validations of satellite retrievals usually focus on an evaluation of the AOD, with less attention paid to understanding error sources from the variation of aerosol single scattering properties in real atmosphere [21,22]. It was found that the temporal variations of aerosol scattering properties in regions such as southern Africa caused a seasonal shift of MODIS AOD biases [23]. To date, how the change of aerosol properties in China influences MODIS AOD bias at different spatial and temporal scales remains unclear, and is the focus of this study.

We conduct a comprehensive analysis of aerosol single scattering properties in eastern China, and examine their impacts on biases in MODIS aerosol retrievals. Section 2 introduces the Aerosol Robotic Network (AERONET) and MODIS aerosol data sets used. Monthly variations of typical aerosol properties in six sites of eastern China are described in Section 3.1. Section 3.2 investigates the monthly bias of MODIS AOD and its connection with aerosol properties. The influence of decadal variations in aerosol properties on satellite retrievals is discussed specially in Section 3.3. The main purpose of this work is to present a reference for aerosol model assumptions in satellite retrievals over China.

\section{Data and Methods}

\subsection{AERONET Aerosol Data Sets}

The AERONET is a worldwide network of sun photometers that provides continuous observations and inversions of aerosol optical and microphysical properties [4]. By measuring the direct solar irradiance, AOD can be acquired with a high accuracy of $0.01-0.02$, which is usually taken as the "true" value in ground validation. With skylight observations, microphysical and single scattering parameters 
such as volume size distribution, SSA, and phase function can be retrieved [9]. The retrieval error of the size distribution is within $10 \%$ of the maximum value in the median particle size range $(0.1-7 \mu \mathrm{m})$. To obtain sufficient information, the SSA has to be retrieved in high aerosol loading (AOD $440 \mathrm{~nm}>0.4$ ) and solar zenith angle $\left(>50^{\circ}\right)$ with an accuracy of $\sim 0.03$.

Aerosol data from six AERONET sites in typical regions were selected to investigate variations in aerosol optical properties in eastern China (Figure 1). There are nearly 15 years of continuous observations from the Beijing site since 2001, and 10 years of observations from the Xianghe, Taihu, and Hongkong sites from 2005 at Level 2.0 (cloud-screened and quality-assured), respectively. Observation over 4 years is available in Xuzhou from 2013 at Level 1.5 (cloud-screened). More than one year's observation exists in Qiandaohu at Level 1.5 from 2007 to 2009, but the inversions are much fewer, which is mainly used for reference here. The monthly mean values of aerosol microphysical and optical parameters are analyzed to show the temporal variations of the aerosol scattering properties. Outliers caused by few available inversions during the cloudy season are examined and removed. To match with the satellite data, the spatial average of MODIS AOD in $5 \times 5$ pixel around the ground site is compared with the temporal mean values of AERONET inversions within \pm 30 min of the satellite's passing time [24]. Since there is no $550 \mathrm{~nm}$ band in the sun photometers, we interpolate the AOD from the nearest bands on the two sides of $550 \mathrm{~nm}$ with their Ångström exponent.

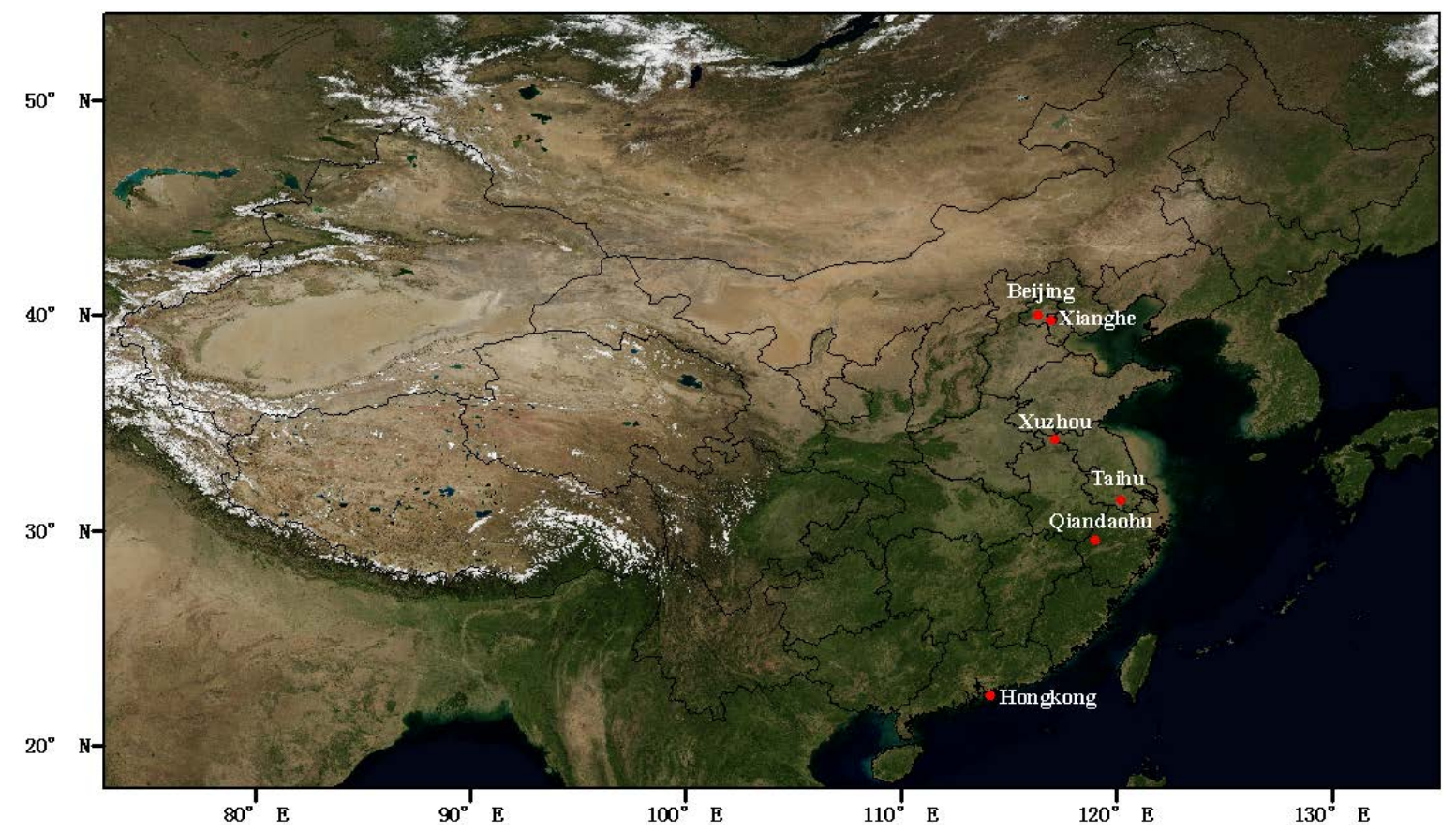

Figure 1. Geographic location of the six typical Aerosol Robotic Network (AERONET) sites in eastern China. Beijing: megacity site, Xianghe: background site among megacities, Xuzhou: industrial city site in hinterland of northern China, Taihu: background site of the Yangtze River Delta, Qiandaohu: background site of southern China, Hongkong: coastal megacity site in southern China.

\subsection{MODIS Aerosol Data Sets}

The MODIS sensor onboard the Terra satellite from 2000 and the Aqua satellite from 2002 provides daily global detection of reflected and emitted radiance from the Earth-atmospheric system with a broad spectrum range of $0.4-14.4 \mu \mathrm{m}$, fine spatial resolution at 250-1000 $\mathrm{m}$, and swath width of $\sim 2330 \mathrm{~km}$. MODIS aerosol retrieval over land employs the Dark Target (DT) and Deep Blue (DB) algorithms over dense vegetation and bright surfaces, such as urban and deserts, respectively. In recent MODIS C6 aerosol products, DB retrieval has been expanded to all cloud-free and snow/ice-free regions, and a merged AOD data product combining DT and DB retrievals developed over dense 
vegetation regions [25]. To raise the signal-to-noise ratio and minimize cloud contamination, DT retrieval is performed over an area of $20 \times 20500 \mathrm{~m}$ pixels or at a nominal spatial resolution of AOD at $10 \times 10 \mathrm{~km}$. By contrast, DB aerosol properties are retrieved at $1 \mathrm{~km}$ resolution and then averaged to $10 \times 10 \mathrm{~km}$ scale. Since the sensor degradation of the MODIS aboard Terra is much larger than that of Aqua, only aerosol data from the Aqua MODIS is used here [26].

The DT algorithm retrieves aerosol properties over dense vegetation utilizing a linear relationship in surface reflectance between visible and shortwave infrared bands [11]. With weighted fine and coarse aerosol models (that describe aerosol single scattering properties), the AOD and fine-mode AOD fraction are retrieved by matching the calculated apparent reflectance with satellite TOA spectral reflectance in $0.47,0.67$, and $2.1 \mu \mathrm{m}$. The surface reflectance relationship between 0.67 and $2.1 \mu \mathrm{m}$ varies with view geometry and surface type. One coarse aerosol model and one of three fine aerosol models are employed in DT retrieval (Table 1), and the fine aerosol model is prescribed by location and season [27]. As a by-product, surface reflectance in $2.12 \mu \mathrm{m}$ is also retrieved. Global validation shows that more than $66 \%$ of the DT retrievals are within the error envelope of $\pm(0.05+15 \%$ AOD) [25].

To retrieve the AOD over a bright surface, the DB algorithm utilizes a pre-calculated surface reflectance database in blue channels, where the surface reflectance is much lower than in longer channels [10]. The surface reflectance database in the C6 DB algorithm has been improved as a function of season, normalized difference vegetation index (NDVI), and scattering angle [28]. Similarly to DT, the DB algorithm divides the globe into several regions, and assumes fixed aerosol types in certain areas such as dust and smoke models in early retrievals over East Asia (Table 1). In cases of mixed aerosol types, two unknowns, the AOD and the Angström exponent (and hence, the AOD fraction of aerosol types) are retrieved from TOA radiance in 0.41 and $0.47 \mu \mathrm{m}$. For heavy dust loading conditions, the radiance in the red band at $0.67 \mu \mathrm{m}$ is added to further retrieve the SSA in the blue bands. The global bias of DB AOD is approximately within $\pm\left(0.03+0.2\right.$ AOD $\left._{\text {MODIS }}\right)$ [29].

Table 1. List of typical optical parameters in aerosol models used in MODIS Dark Target (DT) and Deep Blue (DB) algorithms [10,25]. The DT aerosol model varies with aerosol loading and the case of $\mathrm{AOD}_{550}=0.5$ is presented here; $\mathrm{R}$ denotes the effective radius in the DT model, and for DB it is the mean radius; since information of Collection $6 \mathrm{DB}$ aerosol model is not available, the original version is used for reference. SSA, single scattering albedo.

\begin{tabular}{ccccccc}
\hline Aerosol Model & Algorithm & SSA, 412 nm & SSA, 470 nm & SSA, 660 nm & R, $\boldsymbol{\mu m}$ & Standard Deviation, $\boldsymbol{\mu m}$ \\
\hline Dust/Spheroid & DT & - & 0.94 & 0.96 & 0.68 & - \\
Absorbing/Smoke & DT & - & 0.88 & 0.85 & 0.256 & - \\
Moderately Absorbing & DT & - & 0.93 & 0.91 & 0.261 & - \\
Nonabsorbing/Urban-Industrial & DT & - & 0.95 & 0.94 & 0.207 & 1.0 \\
Dust/Spheroid & DB & 0.91 & 0.96 & - & - & -14 \\
Smoke & DB & 0.90 & 0.89 & - & - & - \\
"whiter" Dust/Spheroid & DB & 0.98 & 0.99 & $\approx 1.0$ & - & - \\
"redder" Dust/Spheroid & DB & 0.91 & 0.94 & $\approx 1.0$ & & - \\
\hline
\end{tabular}

\section{Results and Analysis}

\subsection{Aerosol Optical Properties in Eastern China}

The angular distribution of scattered light largely depends on particle size, which associates closely with emission sources [9]. Figure 2 shows the variations of monthly volume size distribution in typical regions of eastern China. There is a notable bimodal distribution in all the sites, with a large spatial and temporal difference. Coarse particles are dominant in northern China (Beijing, Xianghe, and Xuzhou) and the Yangtze River Delta (YRD, Taihu) during spring. Although there are few dust storm events in eastern China every year, floating dust transported from the deserts of East Asia is prevalent over northern China [14]. The vertical distribution of the floating dust particles is very inhomogeneous [30]. Hence, the fraction of coarse particles may not be considerable in ground sampling, but can be significant in column observations. The contribution of coarse particles also 
shows large monthly variations even in Qiandaohu in the north part of southern China, and in some months, fine and coarse particles have a nearly equivalent volume. By contrast, fine particles play a major role in July and August, modulated mainly by anthropogenic emissions and photochemical processes. It should be noted that the volume of coarse particles is similar to that of fine aerosols during fall and winter in northern China, which indicates the common mixing of dust and anthropogenic pollutants. While Hongkong is dominated by fine aerosol all year round, the fraction of coarse aerosols is still significant $(\sim 30 \%)$, and has much less monthly or seasonal variation, suggesting the influence of sea salt. Indeed, the fraction of coarse particles in Hongkong is higher than its counterpart in the continental background site of Qiandaohu during September. Similar observations also exist in other coastal sites, such as Zhoushan in the YRD [17].
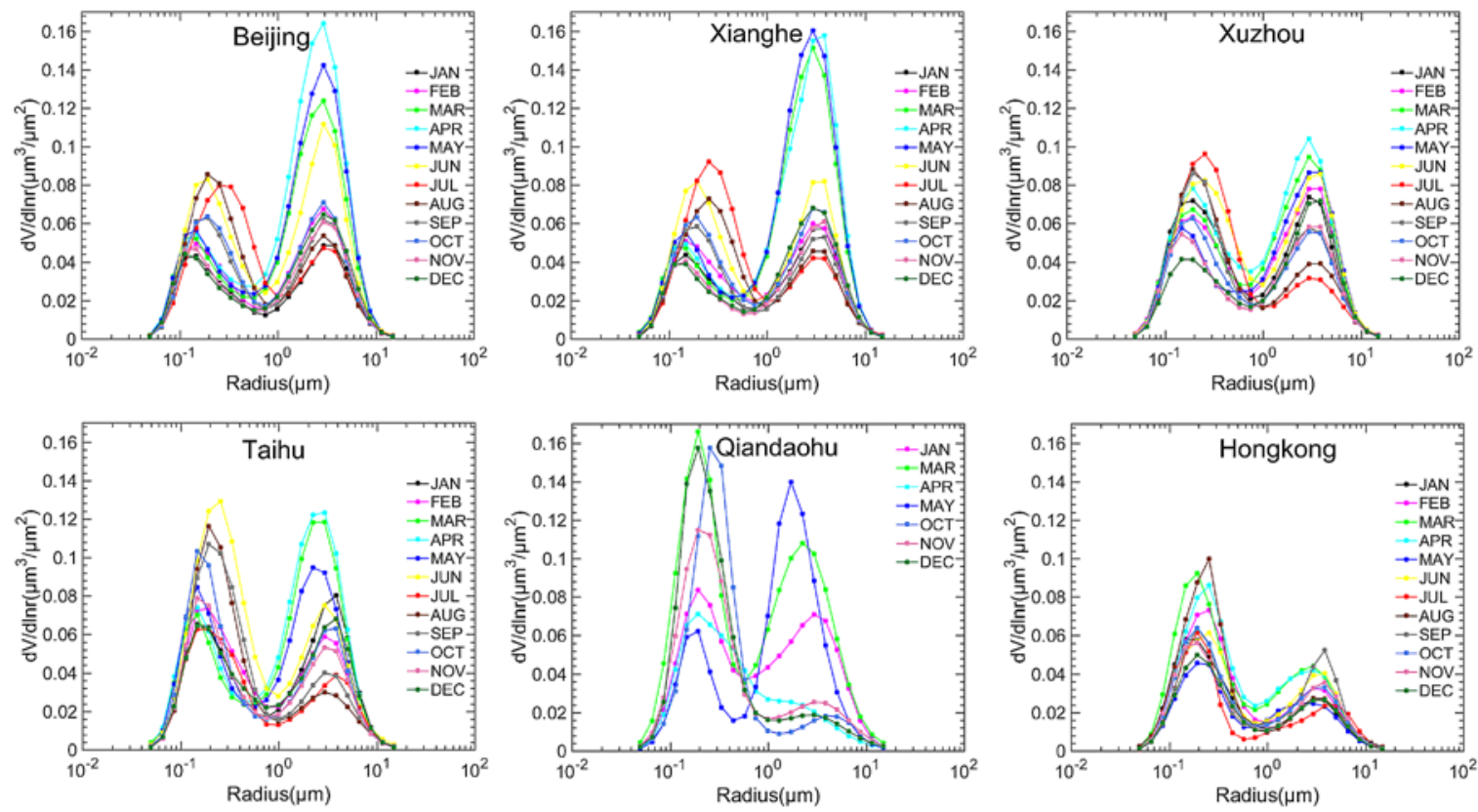

Figure 2. Monthly mean value of volume size distribution in AERONET sites of Beijing, Xianghe, Xuzhou, Taihu, Qiandaohu, and Hongkong, respectively.

Aerosol SSA exhibits large temporal variations in eastern China (Figure 3). The SSA values at $440 \mathrm{~nm}$ in northern China range from $\sim 0.85$ in the winter season (that uses coal-burning for heating) to $\sim 0.95$ in humid summer. The SSA increases gradually from January, reaches its maximum value in July, and then begins to decrease. In southern China (Qiandaohu and Hongkong), where no coal-burning is needed for heating in winter, the temporal change of the SSA is smaller $(\sim 0.90-0.95)$, but there is also an obvious increase in the SSA during summer associated with enhanced hygroscopic growth in humid conditions. It is worth noting that the SSA in Qiandaohu may be not typical due to only few available inversion data from AERONET in most months. Overall, for most sites, the variations of the SSA show a larger dependence on wavelength in winter and spring but a smaller dependence in summer and fall, which can caused by a mixture of anthropogenic aerosols and coarse dust in winter and spring [31]. Large daily variations in the SSA also exist in Beijing and Hongkong, where regional transport usually superposes on local pollution. 

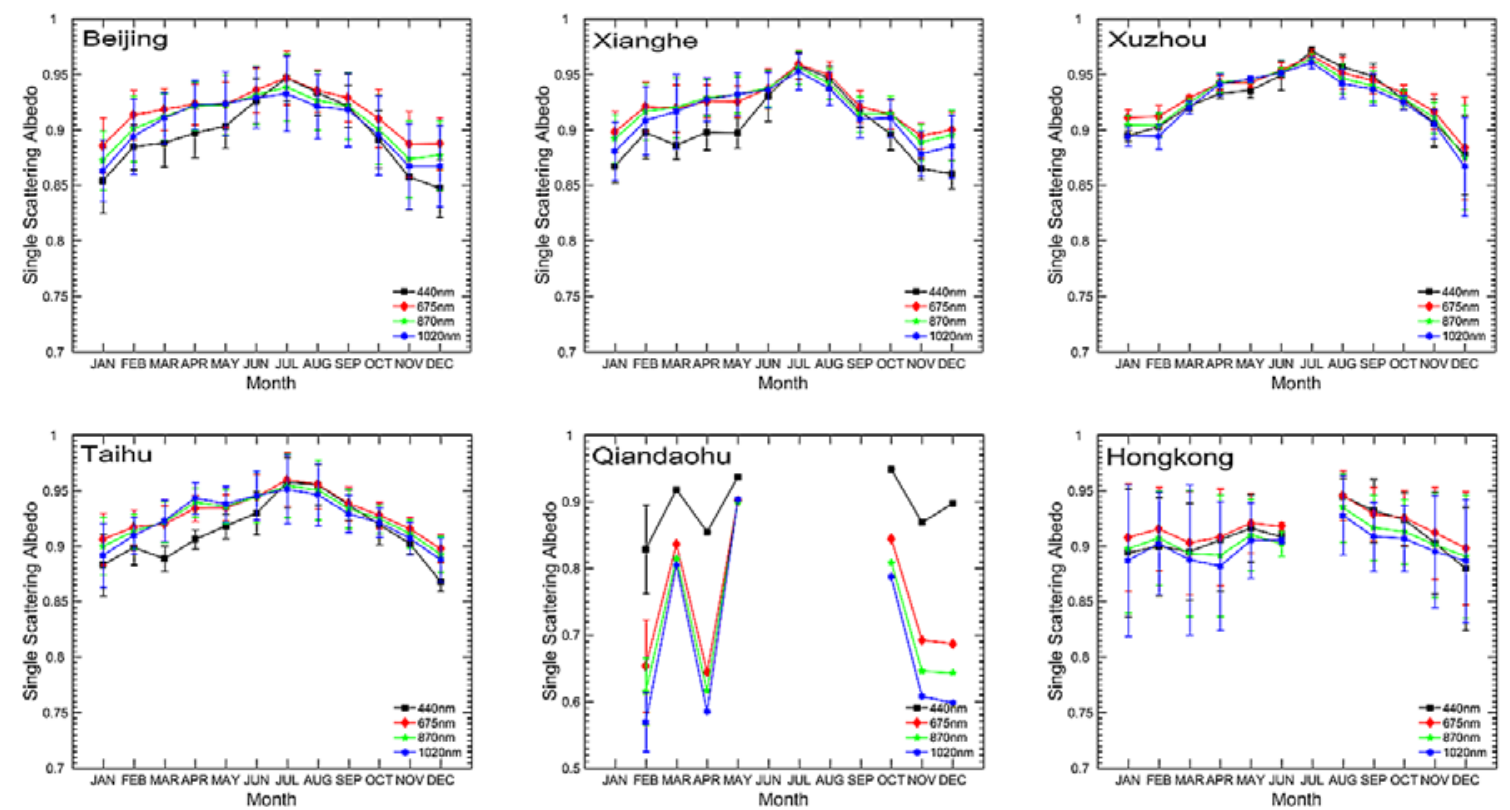

Figure 3. Monthly mean values of single scattering albedos in eastern China. The monthly values with available daily values of no more than 3 days every year were deleted.

Corresponding to the temporal variation of size distribution and SSA, and relevant to the satellite retrieval algorithm that uses backscattered solar radiation, Figure 4 shows the variation of phase function at backward direction over different AEROENT sites. In northern China, the monthly phase function exhibits approximately $20-30 \%$ of its variation at around $90-150^{\circ}$ in the back-scattering directions. It can be seen that the phase function is lowest in summer (red lines) with fine particles dominant and highest in spring (blue lines) with prevalent dust, reflecting the change of particle size. Indeed, the composite phase function for fine-mode and coarse-mode aerosols in an atmospheric column depends not only on the size distributions for both modes, but also on the scattering optical depth of both modes and the relative weighting. Fine-mode particles have a relatively larger size (due to efficient hygroscopic growth, Figure 2) in summer than in winter, and hence a relatively smaller phase function in the backscattering direction. This size effect, together with more efficient scattering (again due to hygroscopic growth) and a more dominant contribution of fine mode aerosol to the total aerosol optical depth, makes the columnar phase function as whole smaller in summer. Indeed, with a reduction in the fraction of coarse mode particles, the phase function in summer gets lower than 0.1 at Xuzhou and other sites in the south to Xuzhou. Notably, the phase function is much lower at the Qiandaohu site in most scattering angles during October and December, when fine particles are absolutely dominant with very low volume in coarse mode (Figure 2). However, temporal variations of the phase function in Hongkong are much smaller, which is consistent with the particle size distribution. Thus, it is important to make a proper assumption of particle size in aerosol models for satellite retrievals.

To synthesize, the aerosol properties in eastern China exhibit considerable variability over space and time. Spatially, and for the same season, the fraction of the coarse mode deceases from north to south, which leads to weaker backscattering; the SSA in northern China is much lower than that in southern China during winter ( 0.85 vs. 0.90$)$, but is nearly the same in summer ( 0.95). Hence, the aerosol optical properties in northern China are weaker in scattering during winter with more absorption, but the backscattering ability is stronger than in southern China due to the higher phase function associated with the smaller size of fine-mode aerosols (because of less hygroscopic growth, as seen in Figure 2). Temporally, the volume of coarse particles accounts for the higher fraction in northern China and the YRD during winter and spring, and fine particles are dominant in summer and 
fall. There is a notable increase and decease in oscillation for the SSA in eastern China in the transition of dry winter $(\sim 0.85-0.90)$ to humid summer ( 0.95). Corresponding with variations of the particle size, the scattering phase function of the columnar aerosols is high in winter and spring, and more than $20-30 \%$ lower in summer and fall in the backscattering direction.
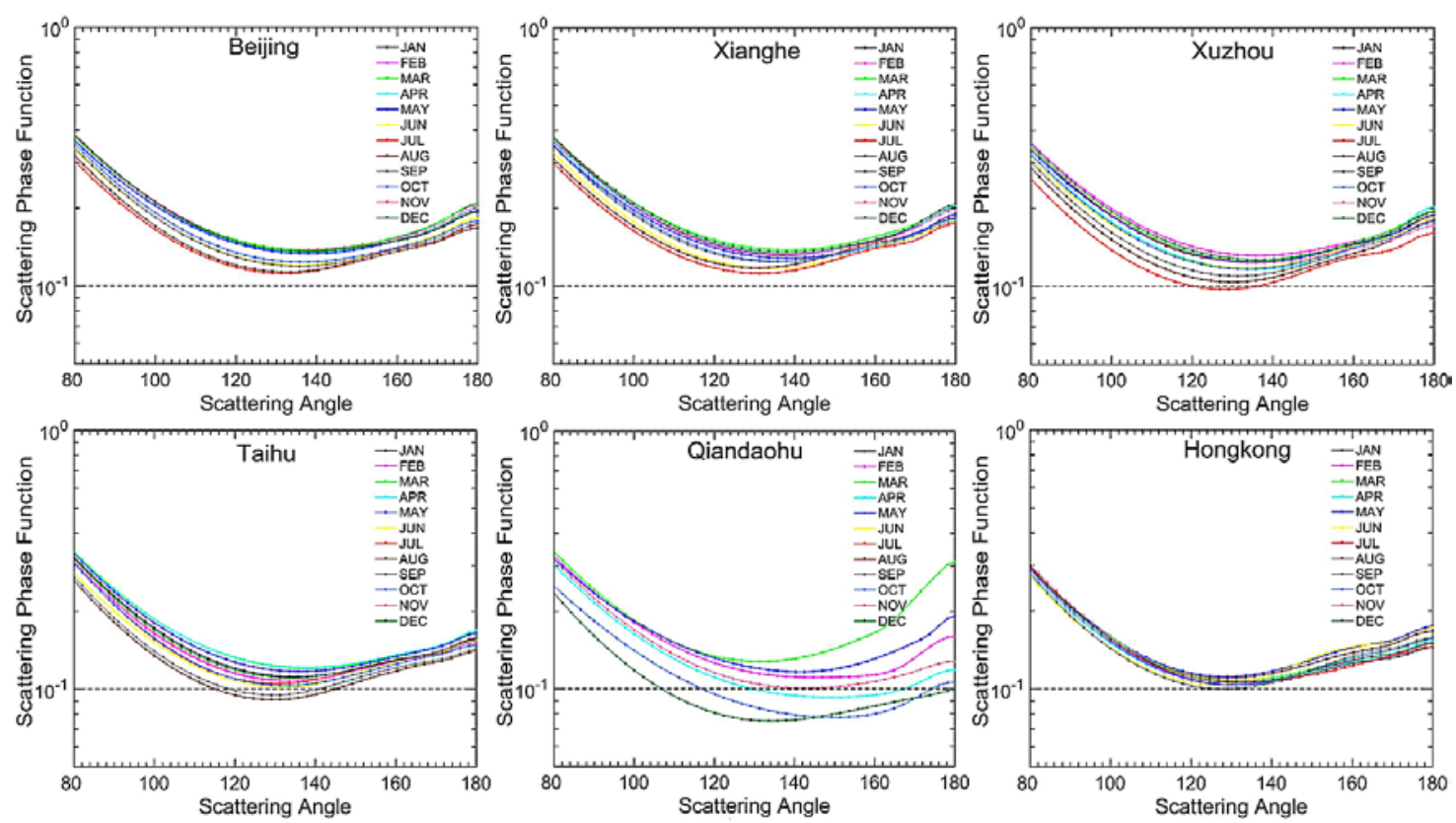

Figure 4. Monthly mean values of scattering phase function at $440 \mathrm{~nm}$ in eastern China.

\subsection{Temporal Characteristics of MODIS Aerosol Retrieval Bias}

Figure 5 shows the daily variations of MODIS DB and DT AOD biases compared with AERONET AOD in northern China (Bejing, Xianghe, and Xuzhou). To reduce the influence from uncertainties of surface reflectance estimation, the bias of satellite retrievals was considered to be robust and analyzed only when the AERONET AOD 550 is $>0.4$. With only a few exceptions, MODIS DB retrieval of the AOD overall has a distinct positive bias in winter (in the range of 0.13-0.24) and slight overestimation in fall, but small negative bias in other seasons (except in Xianghe, Table 2). In particular, a clear switch between positive and negative bias can be found at all of the three sites (Bejing, Xianghe, and Xuzhou) with the same time nodes. In contrast, the AOD in MODIS DT retrievals exhibit obvious overestimation during the whole year, with few values in winter due mostly to the bright surface that is not suitable for retrieval from the DT algorithm (red line Figure 5). Considering that the aforementioned biases are systematic and periodic, it is likely that the difference between the actual and assumed aerosol properties by season can play a dominant role.

Table 2. List of seasonal mean aerosol optical depth (AOD) biases for MODIS DT and DB retrievals when AERONET AOD $550>0.4$ of eastern China. Samples with available values of no more than five were removed to be representative.

\begin{tabular}{ccccccccc}
\hline Site & Winter DT & Spring DT & Summer DT & Fall DT & Winter DB & Spring DB & Summer DB & Fall DB \\
\hline Beijing & - & 0.3 & 0.38 & 0.04 & 0.24 & -0.11 & -0.095 & -0.003 \\
Xianghe & - & 0.353 & 0.42 & 0.201 & 0.153 & -0.04 & 0.1 & 0.064 \\
Xuzhou & 0.299 & 0.31 & 0.26 & 0.273 & 0.137 & 0.006 & -0.176 & 0.088 \\
Taihu & 0.219 & 0.483 & 0.366 & 0.266 & 0.08 & -0.021 & -0.229 & 0.021 \\
Qiandaohu & -0.192 & 0.108 & 0.082 & -0.027 & -0.293 & -0.21 & -0.347 & -0.251 \\
Hongkong & 0.09 & 0.179 & - & 0.137 & -0.113 & -0.274 & -0.5 & -0.218 \\
\hline
\end{tabular}




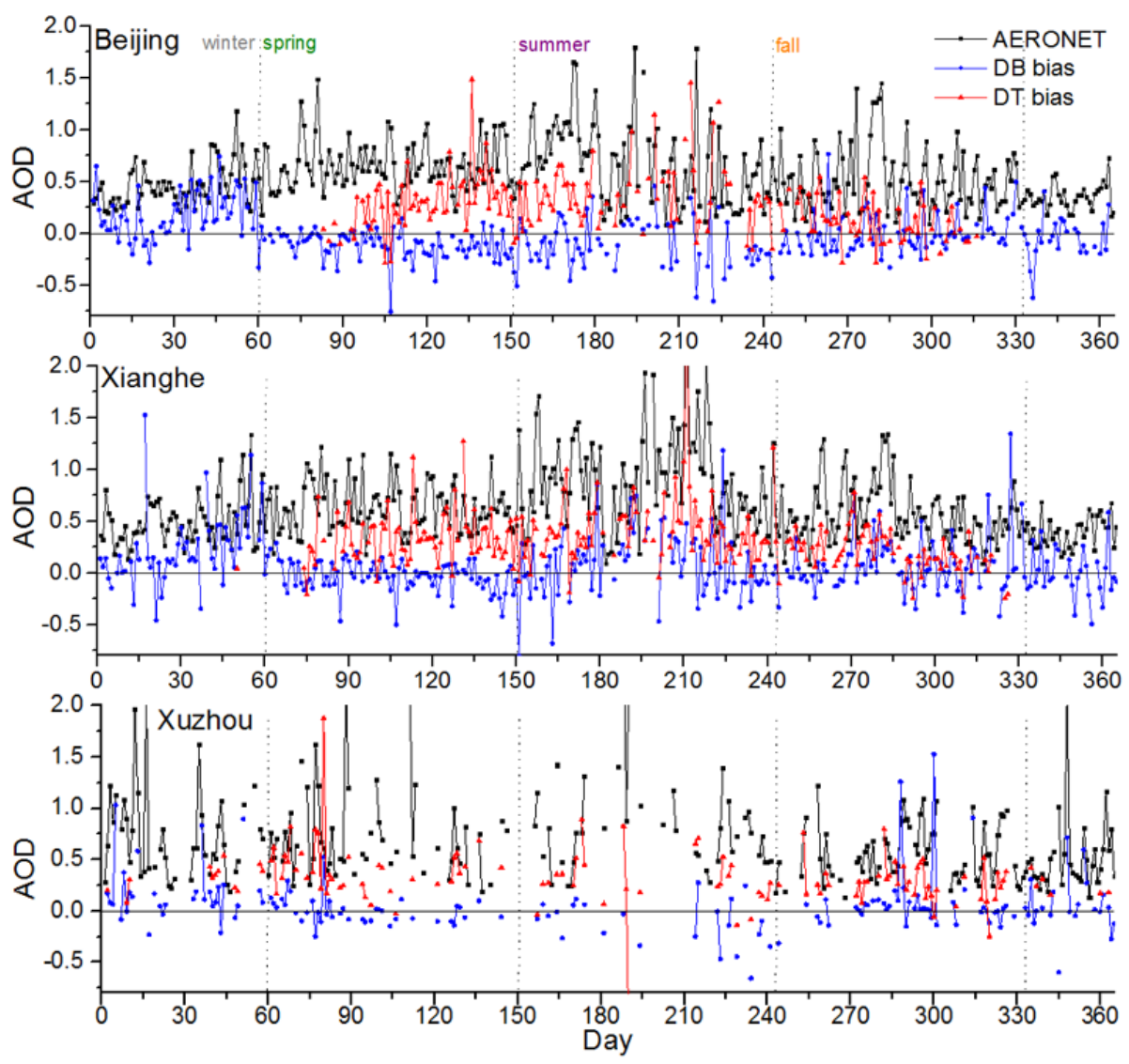

Figure 5. Daily mean values of AERONET AOD (black curve) and bias of MODIS DB and DT AOD (red and blue curves, respectively) when AERONET $\mathrm{AOD}_{550}>0.4$ in northern China.

As shown in Figure 6, the temporal variations of MODIS AOD bias by season in the YRD (Taihu) is similar to their counterparts in northern China. However, there is a notable change in MODIS DB bias in southern China. Differently from the overestimation in northern China and YRD during winter, DB retrievals exhibit a slight negative bias during the whole year in Qiandaohu and Hongkong (Table 2). If the aerosol model was the same as that in northern China, the increase of SSA in southern China would lead to more overestimation in DB retrievals, but the decrease in backscattering can offset the overestimation. Thus, the negative switch in DB AOD bias indicates that the weak backscattering in a phase function can make a more important contribution in southern China. It should be noted the assumed aerosol model can be different in southern China. Therefore, the systematic switch of MODIS DB AOD biases from positive to negative can be caused by changes of aerosol properties or aerosol models in southern China. Correspondingly, when the same aerosol model is used in DT retrieval, the DT bias becomes much smaller with the increase in SSA but decrease in phase function in southern China, and underestimation even appears in Qiandaohu during winter. In addition, significant errors in surface reflectance estimation can also influence the bias in DT retrieval [20].

Since both of the MODIS DB and DT algorithms employ mixed coarse and fine models in aerosol retrieval, the systematic bias of satellite AOD is determined by the combined uncertainties of the mixed models and their respective fractions. Figure 7 shows that MODIS retrieval can generally make a reasonable discrimination of the contribution between fine and coarse aerosol particles except some obvious deviation. The fraction of fine $\mathrm{AOD}_{500}$ in Beijing is around 0.7, with lower values in spring and a higher contribution in summer. The fine aerosol model used for DT and DB retrieval can be inferred from "Aerosol_Type_Land" and "Quality_Assurance_Land", respectively. It is found that a moderately absorbing fine model is assumed in winter and spring in northern China and a non-absorbing one during summer and fall in DT algorithm. While the moderately absorbing model is 
replaced by a non-absorbing one in DT retrieval during winter in Taihu and Qiandaohu, the moderately absorbing model is changed back in Hongkong. A dust and smoke model is employed in DB retrieval in eastern China with aerosol phase function and SSA selected by season and location [28], but detailed information is not available in the current literature.
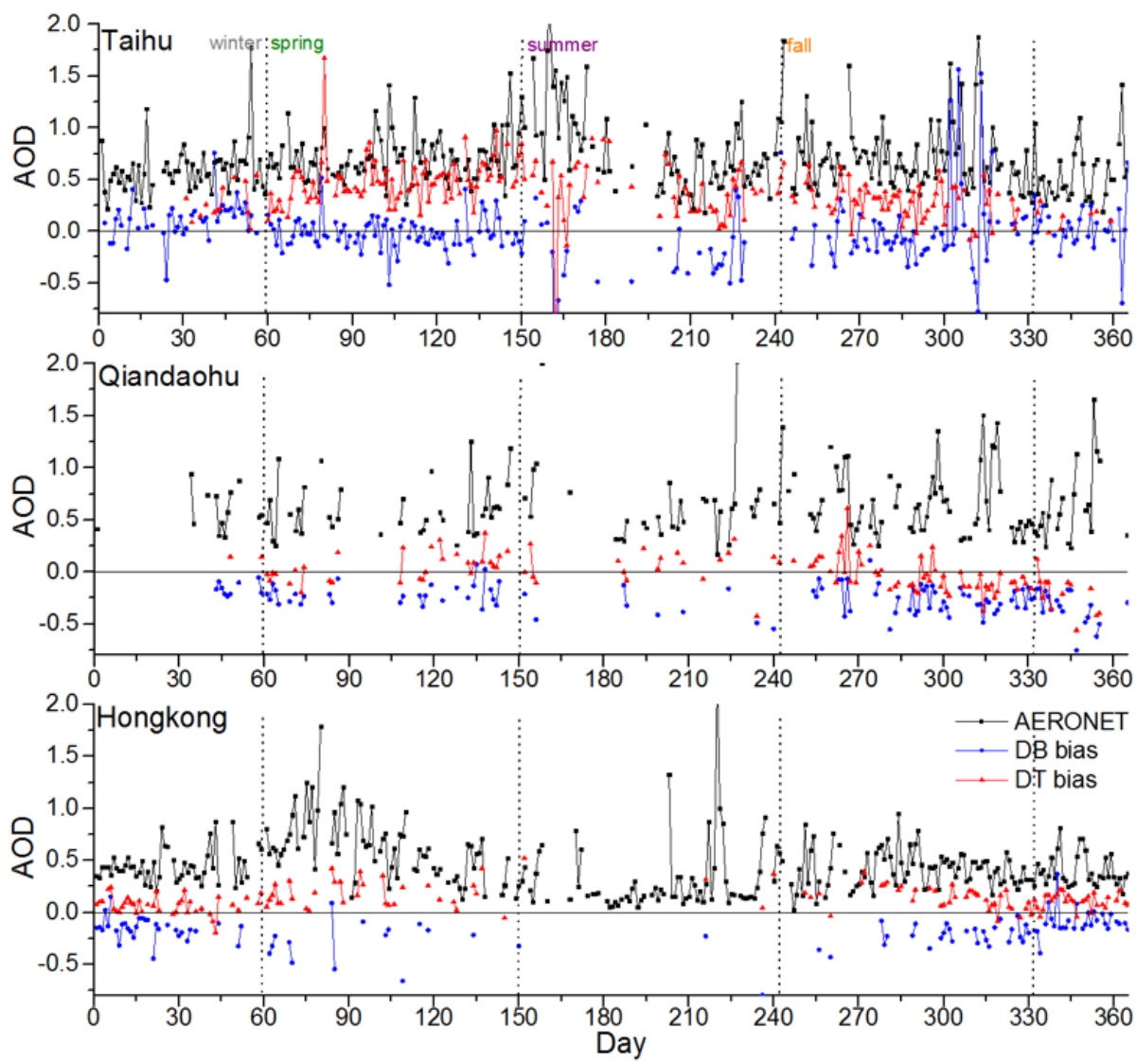

Figure 6. Daily mean values of AERONET AOD (black curve) and bias of MODIS DB and DT AOD (red and blue curves, respectively) when AERONET AOD $550>0.4$ in Taihu, Qiandaohu, and Hongkong.
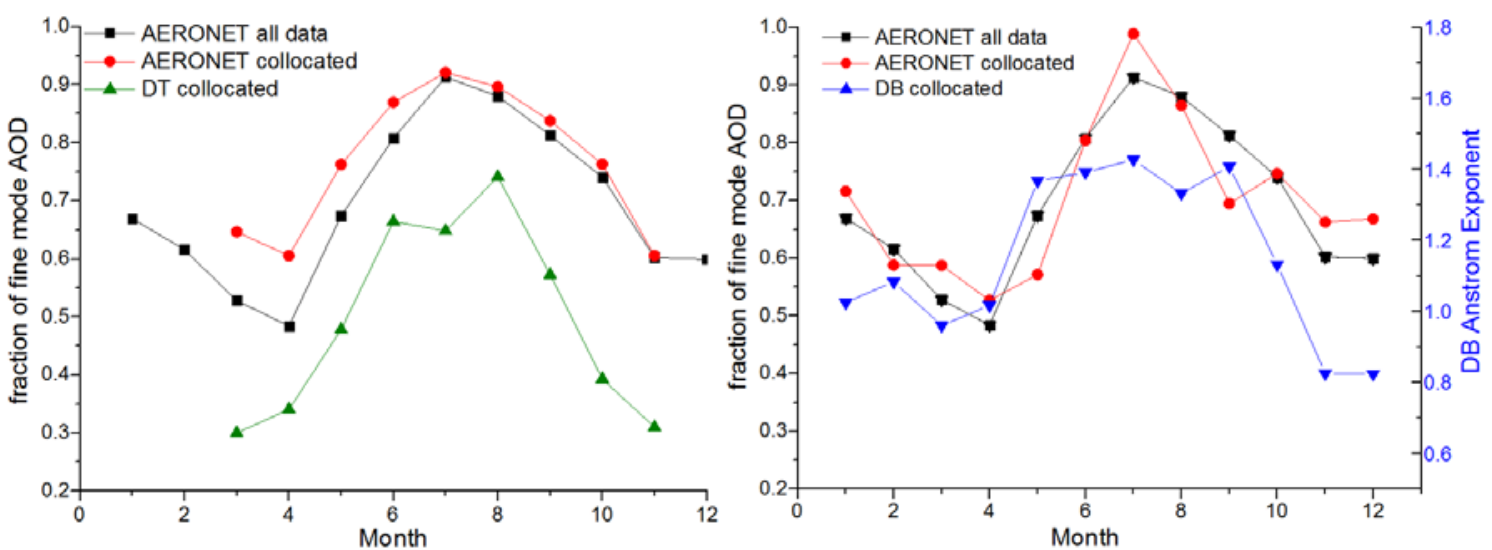

Figure 7. (Left) Comparison of AERONET fine AOD fraction at $500 \mathrm{~nm}$ (black), collocated AERONET (red) and MODIS DT fine mode aerosol fraction at $550 \mathrm{~nm}$ (green), (right) and DB Ångström exponent at 412 and $470 \mathrm{~nm}$ (blue) in Beijing.

Differently from the high spatial dependence in uncertainties induced by surface reflectance estimation in low-AOD conditions [20], MODIS retrieval bias in moderate and high loading exhibits 
clear periodic variations in regional scale, which is associated with the large temporal variations of aerosol properties. Compared with the assumed moderately absorbing fine aerosol model $(\mathrm{SSA}=0.90$ at $670 \mathrm{~nm})$ in DT retrieval during winter and spring, the SSA values in northern China vary from 0.88 to 0.94 , indicating that a large deviation exists in calculating scattering contribution. However, overestimation remains prevalent in DT retrievals when a non-absorbing aerosol model with SSA $=0.95$ is used (Figure $8 \mathrm{a}$ ), demonstrating that the aerosol scattering is generally underestimated Since the magnitude of aerosol scattering is determined by SSA and phase function besides aerosol loading, improper assumptions of aerosol phase function play a major role in this systematic positive AOD bias. The effective radius in the DT algorithm is around $0.25 \mu \mathrm{m}$ for fine mode and $0.68 \mu \mathrm{m}$ for coarse particles (Table 1$)$, which is larger than the fine mode $(\sim 0.13 \mu \mathrm{m})$ in AERONET inversion but much smaller than the coarse mode $(\sim 2.0 \mu \mathrm{m})$ (Figure $8 \mathrm{~b})$. As shown in Figure 4, the backscattering ability is much weaker due to the dominance of fine-mode aerosols with larger size particles in humid summer. The large variations in particle size distribution in eastern China were not well-considered in current MODIS retrievals. Furthermore, at $2.12 \mu \mathrm{m}$, where the fine-mode aerosol effect is much less, the phase function used in the DT algorithm is likely to have a large low bias because the DT algorithm assumes a much smaller coarse-mode particle size (than that which AERONET retrieves). Hence, the underestimation of the phase function at $2.12 \mu \mathrm{m}$ can lead to the spectral slope of retrieved AOD skewing upward, thereby causing an overestimation of AOD in the visible. According to the connections between aerosol properties and the MODIS AOD bias, a preliminary suggestion for the modification of the aerosol models in MODIS retrievals is presented in Table 3.
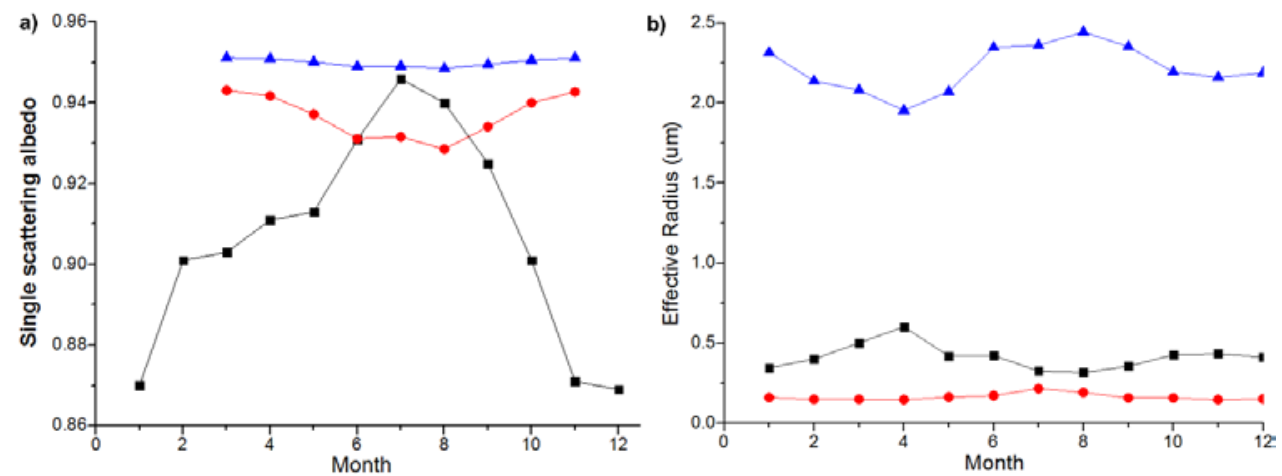

Figure 8. (a) Comparison of monthly mean SSA (black) and MODIS DT SSA from fine (blue for non-absorbing and red for moderately absorbing) and coarse aerosol models at $0.55 \mu \mathrm{m}$; (b) Monthly mean AERONET effective radius $(\mu \mathrm{m})$ for total column (black), fine mode (red), and coarse mode aerosols (blue) in Beijing.

Table 3. Proposed modification for aerosol models of MODIS DT and DB retrievals in eastern China. $\mathrm{S}$ and $\mathrm{P}$ denote SSA and Particle size of fine aerosol models of DT; T signifies the total scattering properties of DB aerosol models (SSA and particle size used unknown); symbols of ' + ', ' $-{ }^{\prime}$, and '*' mean the parameter should be increased, deceased, or unchanged, respectively.

\begin{tabular}{ccccccccc}
\hline Site & Winter DT & Spring DT & Summer DT & Fall DT & Winter DB & Spring DB & Summer DB & Fall DB \\
\hline Beijing & $\mathrm{S}-\mathrm{P}-$ & $\mathrm{S}^{*} \mathrm{P}-$ & $\mathrm{S}^{*} \mathrm{P}-$ & $\mathrm{S}-\mathrm{P}-$ & $\mathrm{T}-$ & $\mathrm{T}+$ & $\mathrm{T}^{*}$ & $\mathrm{~T}-$ \\
Xianghe & $\mathrm{S}-\mathrm{P}-$ & $\mathrm{S}^{*} \mathrm{P}-$ & $\mathrm{S}^{*} \mathrm{P}-$ & $\mathrm{S}-\mathrm{P}-$ & $\mathrm{T}-$ & $\mathrm{T}-$ & $\mathrm{T}-$ & $\mathrm{T}^{*}$ \\
Xuzhou & $\mathrm{S}^{*} \mathrm{P}-$ & $\mathrm{S}+\mathrm{P}-$ & $\mathrm{S}^{*} \mathrm{P}-$ & $\mathrm{S}-\mathrm{P}-$ & $\mathrm{T}-$ & $\mathrm{T}^{*}$ & $\mathrm{~T}+$ & $\mathrm{T}^{*}$ \\
Taihu & $\mathrm{S}-\mathrm{P}-$ & $\mathrm{S}^{*} \mathrm{P}-$ & $\mathrm{S}^{*} \mathrm{P}-$ & $\mathrm{S}-\mathrm{P}-$ & $\mathrm{T}^{*}$ & $\mathrm{~T}^{*}$ & $\mathrm{~T}+$ & $\mathrm{T}^{*}$ \\
Qiandaohu & $\mathrm{S}-\mathrm{P}^{*}$ & $\mathrm{~S}^{*} \mathrm{P}^{*}$ & $\mathrm{~S}+\mathrm{P}^{*}$ & $\mathrm{~S}-\mathrm{P}^{*}$ & $\mathrm{~T}+$ & $\mathrm{T}^{*}$ & $\mathrm{~T}+$ & $\mathrm{T}+$ \\
Hongkong & $\mathrm{S}^{*} \mathrm{P}^{*}$ & $\mathrm{~S}^{*} \mathrm{P}^{*}$ & $\mathrm{~S}_{-} \mathrm{P}^{*}$ & $\mathrm{~S}-\mathrm{P}^{*}$ & $\mathrm{~T}+$ & $\mathrm{T}-$ & $\mathrm{T}+$ & $\mathrm{T}+$ \\
\hline
\end{tabular}




\subsection{Decadal Variations of the Aerosol Optical Properties and MODIS AOD Bias}

Besides the large seasonal variations caused by dust transport, winter coal-burning heating, and meteorological conditions, the concurrent economic development and government regulation for improving air quality have brought dramatic changes in anthropogenic emissions in eastern China during the last decades [19,32]. Figure 9 shows an obvious decreasing trend $(-0.11$ per decade) of AOD in Beijing, where great efforts has been made to reduce local and surrounding emissions. Another prominent feature is that the total effective radius in Beijing becomes smaller with control measures on primary emissions. Moreover, there is a large increase $(\sim 0.05)$ in the SSA of the aerosol particles, which is consistent with the considerable reduction ( 38\%) of black carbon [33]. These striking changes in aerosol scattering ability and angular distribution can to lead to serious deviations from those of the fixed fine aerosol model for satellite retrievals.

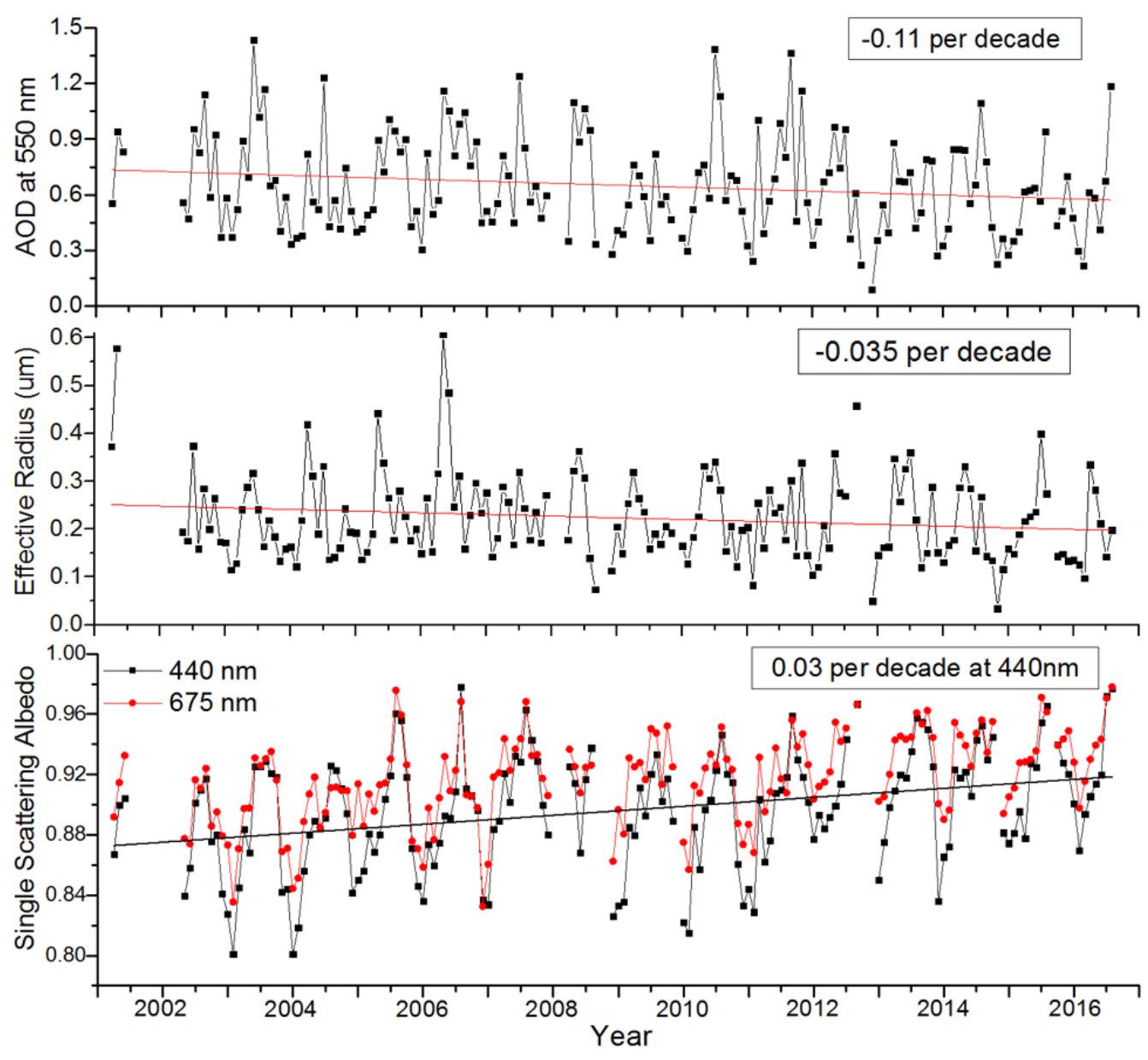

Figure 9. Variations of monthly AOD at $550 \mathrm{~nm}$, total effective radius, and single scattering albedo in Beijing from 2001 to 2016.

Figure 10 displays the trends of MODIS retrieval bias in moderate and high AOD conditions from 2003 to 2016. It is surprising that the overestimation of DT retrievals becomes larger with time. The SSA values in Beijing become higher than both of these in the moderately absorbing and weakly absorbing fine models used in the DT algorithm (Figure 9), leading to more overestimation of aerosol loading by underestimating the aerosol scattering contribution. By comparison, variations of DB retrieval bias are relatively complicated, with negative bias getting much smaller and positive bias becoming slightly larger. While the obvious decrease in the underestimation of the DB retrievals during spring and summer can be associated with the increasing SSA in Beijing, the overestimation in 
fall and winter can be enlarged due to further difference with the underestimated scattering ability in the DB aerosol model. Such variations of aerosol optical properties can cause a difference of $>0.1-0.2$ in annual mean AOD, which exerts non-negligible uncertainties in analyzing the trends of aerosol loading with satellite retrievals.

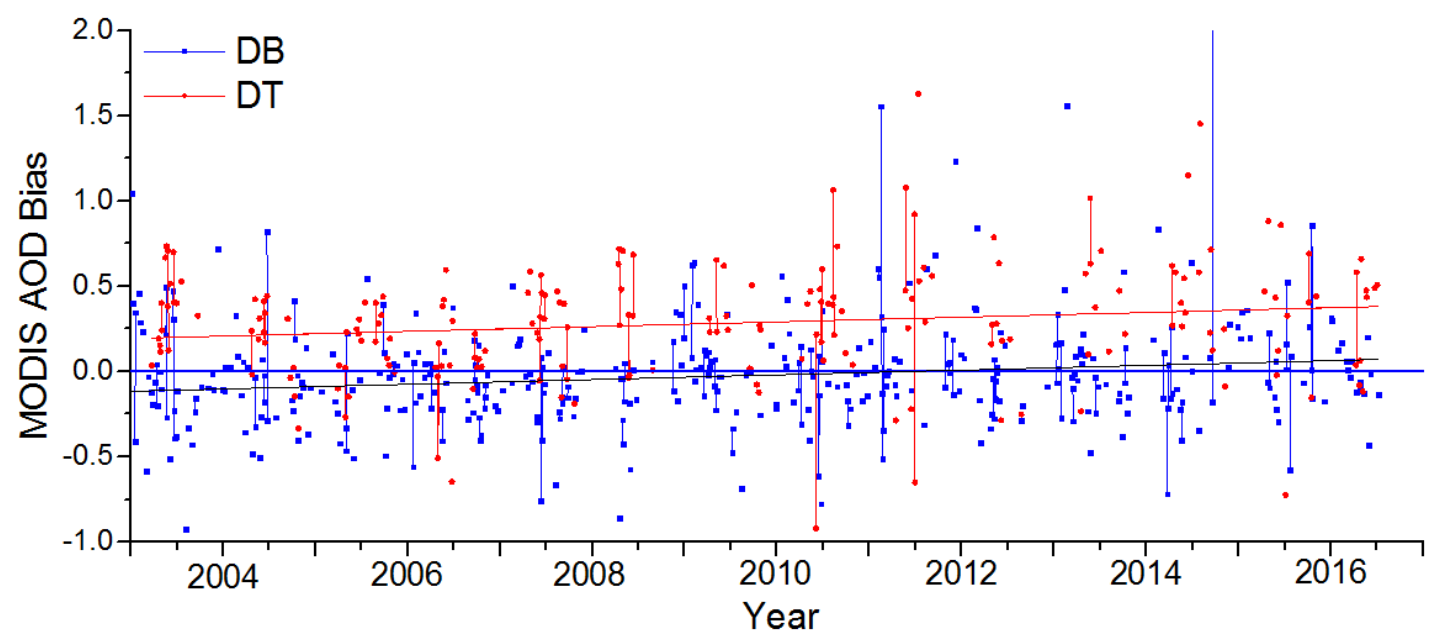

Figure 10. Daily bias of Aqua MODIS C6 DB and DT AOD (AOD $550>0.4)$ in Beijing from 2003 to 2016.

\section{Discussions}

As shown above, the complicated aerosol properties in eastern China, with both striking seasonal and yearly changes, have caused a large bias in MODIS aerosol retrievals. The several aerosol models in the MODIS DT and DB algorithms can represent most situations in the world [25,28], but obviously miss some unique properties of the aerosol particles, such as the prevalent coarse dust in eastern China. Different assumptions of the aerosol properties lead to distinct deviations between the DB and DT retrievals. Although detailed information of MODIS aerosol models, especially for the DB algorithm, is not available, their overall performance from the combined contribution of the assumed SSA and the scattering phase function can be inferred from the AOD bias of the satellite retrievals. A clear switch in MODIS DB retrieval bias from spring can be caused by the seasonal change of assumed aerosol models (Figure 5). However, to identify the specific error sources, detailed information, including both the SSA and phase function (or refractive index and particle size), is necessary to compare with ground observations.

The lookup table of aerosol properties is significant for the efficiency of MODIS operational global daily retrieval. Despite the large spatial and temporal variations of aerosol properties in eastern China, reasonable assumptions can constrain the typical properties with mixed and fixed aerosol models. In the other hand, the yearly variations of aerosol properties have to be considered by time or a more flexible combination of aerosol models. More available information, such as multi-angle and polarization observations, can enable investigators to better capture the aerosol properties in satellite retrievals. Ground observations in a sufficient number of sites are needed to characterize the geographic difference of aerosol properties. Luckily, there have been many observations, such as the China Aerosol Remote Sensing Network (CARSNET) [16,18], which can substantially improve MODIS retrieval bias in China.

\section{Conclusions}

MODIS aerosol products have been widely used in climate and air pollution research due to their near daily global observations and coverage since 2000, and at the same time have received much concern about their uncertainties. Despite reasonable accuracy at the global scale, the performance of MODIS retrievals in China has suffered deeply from the complicated and dramatic aerosol properties. 
Differently from previous validations for general evaluation, here we present a special study on aerosol scattering properties in typical regions of eastern China and the dependence of MODIS C6 aerosol retrieval bias on ground-based observations over six AERONET sites. Striking systematic deviation is found in both the MODIS DT and DB retrievals, with distinct biases caused by their respective aerosol models. However, the fraction of the weighted fine and coarse models can be roughly estimated with the MODIS retrievals.

The scattering ability of the aerosol models is constrained by both SSA and scattering phase function. Despite the high SSA ( 0.95) assumed in summer and fall, DT retrievals in eastern China exhibit obvious overestimation rather than underestimation during the whole year. The effective radius of fine aerosol models used in DT retrievals $(\sim 0.26 \mu \mathrm{m}$ when AOD $=0.5)$ is much larger than the actual size $(\sim 0.13 \mu \mathrm{m})$ in ground observations, which leads to a serious overestimation of aerosol loading due to the assumed low scattering ability. Meanwhile, the smaller particle size $(\sim 0.68 \mu \mathrm{m}$ when AOD $=0.5)$ assumed in the DT coarse model is much smaller than that $(\sim 2.0 \mu \mathrm{m})$ used in ground inversions. Considering the negligible scattering contribution of fine aerosols in shortwave infrared bands, the underestimation of the phase function at $2.1 \mu \mathrm{m}$ can further aggravate the overestimation of aerosol loading. Correspondingly, DT bias gets much smaller in southern China, which is dominated by fine particles with larger size in humid conditions. By comparison, positive bias is dominant in DB retrieval during fall and winter with smaller negative bias in spring and summer, indicating the clear difference caused by the seasonal aerosol models. On the other hand, the yearly variations of aerosol properties lead to considerable changes in the magnitude of MODIS AOD bias. While the DT bias gets larger with increasing SSA from 2003 to 2016, the negative bias in DB retrieval becomes much smaller in spring and summer.

Our results demonstrate that the unique aerosol properties in eastern China should be included in satellite retrievals. Since MODIS DT aerosol models were fixed within half a year in eastern China, the notable variations of monthly aerosol scattering properties have caused considerable retrieval bias, since even deviations of SSA can partly cancel out the errors from an assumed phase function. On the other hand, the distinct spatial difference in particle size and SSA demonstrates that the assumed aerosol models should constrain such geographic variations rather than employ one fixed fine aerosol model in the whole of eastern China. In addition, the obvious changes in yearly aerosol scattering properties have to be taken into account. The DT algorithm utilizes a combination of one fine and one coarse aerosol model to characterize real situations. Despite the substantial variations, aerosol properties in eastern China exhibit clear change patterns in spatial and temporal scales. To establish proper and flexible aerosol models, the division of geographic sectors (e.g., northern and southern China), time range (e.g., seasonal), and typicality of the combined aerosol models should be considered based on the aerosol scattering properties and radiative transfer simulations.

Acknowledgments: This study was supported by the National Science Foundation of China (Grant No. 41401482, 41571347). Z. Wang was supported by National High Technology Research and Development Program of China (Grant No. 2014AA06A511). J. Tao was supported by the public welfare science and technology project of Beijing (Z161100001116013). J. Wang and X. Xu are supported by the research funds from the University of Iowa. The authors are grateful for the MODIS aerosol team, AERONET team, and site PIs (H. B. Chen, P. Goloub, P. Wang, X. Xia, L. Wu, R. Ma, J. Hong, and J. E. Nichol) for the data used in this investigation.

Author Contributions: Minghui Tao, Zifeng Wang, Jinhua Tao, and Liangfu Chen conceived and designed the experiments; Minghui Tao, Can Hou, Lunche Wang, and Hao Zhu performed the experiments and analyzed the data; Minghui Tao wrote the paper; Jun Wang and Xiaoguang Xu provided guidance to the project, reviewed and edited the paper.

Conflicts of Interest: The authors declare no conflict of interest.

\section{References}

1. Kaufman, Y.J.; Tanre, D.; Boucher, O. A satellite view of aerosols in the climate system. Nature 2002, 419, 215-223. [CrossRef] [PubMed] 
2. Pope, C.A.; Dockery, D.W. Health Effects of Fine Particulate Air Pollution: Lines that Connect. J. Air Waste Manag. Assoc. 2006, 56, 709-742. [CrossRef] [PubMed]

3. IPCC. Climate Change 2013: The Physical Science Basis. Contribution of Working Group I to the Fifth Assessment Report of the Intergovernmental Panel on Climate Change; Stocker, T.F., Qin, D., Plattner, G.K., Tignor, M.M.B., Allen, S.K., Boschung, J., Nauels, A., Xia, Y., Bex, V., Midgley, P.M., Eds.; Cambridge University Press: Cambridge, UK; New York, NY, USA, 2013; 1535 p.

4. Holben, B.N.; Eck, T.F.; Slutsker, I.; Tanre, D.; Buis, J.P.; Setzer, A.; Lavenu, F. AERONET-A Federated Instrument Network and Data Archive for Aerosol Characterization. Remote Sens. Environ. 1998, 66, 1-16. [CrossRef]

5. Kaufman, Y.J.; Tanré, D.; Remer, L.A.; Vermote, E.F.; Chu, A.; Holben, B.N. Operational remote sensing of tropospheric aerosol over land from EOS moderate resolution imaging spectroradiometer. J. Geophys. Res. 1997, 102, 17051-17068. [CrossRef]

6. Diner, D.J.; Martonchik, J.V.; Kahn, R.A.; Pinty, B.; Gobron, N.; Nelson, D.L.; Holben, B.N. Using angular and spectral shape similarity constraints to improve MISR aerosol and surface retrievals over land. Remote Sens. Environ. 2005, 94, 155-171. [CrossRef]

7. Torres, O.; Tanskanen, A.; Veihelmann, B.; Ahn, C.; Braak, R.; Bhartia, P.K.; Veefkind, P.; Levelt, P. Aerosols and surface UV products from Ozone Monitoring Instrument observations: An overview. J. Geophys. Res. 2007, 112. [CrossRef]

8. Winker, D.M.; Vaughan, M.A.; Omar, A.; Hu, Y.; Powell, K.A.; Liu, Z.; Hunt, W.H.; Young, S.A. Overview of the CALIPSO Mission and CALIOP Data Processing Algorithms. J. Atmos. Ocean. Technol. 2009, 26, 2310-2323. [CrossRef]

9. Dubovik, O.; Holben, B.; Eck, T.F.; Smirnov, A.; Kaufman, Y.J.; King, M.D.; Tanre, D.; Slutsker, I. Variability of absorption and optical properties of key aerosol types observed in worldwide locations. J. Atmos. Sci. 2002, 59, 590-608. [CrossRef]

10. Hsu, N.C.; Tsay, S.C.; King, M.D.; Herman, J.R. Aerosol properties over bright-reflecting source regions. IEEE Trans. Geosci. Remote Sens. 2004, 42, 557-569. [CrossRef]

11. Levy, R.C.; Remer, L.A.; Mattoo, S.; Vermote, E.F.; Kaufman, Y.J. Second generation operational algorithm: Retrieval of aerosol properties over land from inversion of Moderate Resolution Imaging Spectroradiometer spectral reflectance. J. Geophys. Res. 2007, 112, 3710-3711. [CrossRef]

12. Li, Z.; Li, C.; Chen, H.; Tsay, S.C.; Holben, B.; Huang, J.; Xia, X. East Asian Studies of Tropospheric Aerosols and their Impact on Regional Climate (EAST-AIRC): An overview. J. Geophys. Res. Atmos. 2011, 116, D00K34. [CrossRef]

13. Zhang, X.Y.; Wang, Y.Q.; Niu, T.; Zhang, X.C.; Gong, S.L.; Zhang, Y.M.; Sun, J.Y. Atmospheric aerosol compositions in China: Spatial/temporal variability, chemical signature, regional haze distribution and comparisons with global aerosols. Atmos. Chem. Phys. 2012, 11, 779-799. [CrossRef]

14. Tao, M.H.; Chen, L.F.; Su, L.; Tao, J.H. Satellite observation of regional haze pollution over the North China Plain. J. Geophys. Res. 2012, 117, D12203. [CrossRef]

15. Tao, M.H.; Chen, L.F.; Wang, Z.F.; Tao, J.H.; Su, L. Satellite observation of abnormal yellow haze clouds over East China during summer agricultural burning season. Atmos. Environ. 2013, 79, 632-640. [CrossRef]

16. Che, H.; Zhang, X.Y.; Xia, X.; Goloub, P.; Holben, B.; Zhao, H.; Damiri, B. Ground-based aerosol climatology of China: Aerosol optical depths from the China Aerosol Remote Sensing Network (CARSNET) 2002-2013. Atmos. Chem. Phys. 2015, 15, 7619-7652. [CrossRef]

17. Xie, Y.; Li, Z.; Li, D.; Xu, H.; Li, K. Aerosol Optical and Microphysical Properties of Four Typical Sites of SONET in China Based on Remote Sensing Measurements. Remote Sens. 2015, 7, 9928-9953. [CrossRef]

18. Xin, J.; Wang, Y.; Pan, Y.; Ji, D.; Liu, Z.; Wen, T.; Wang, P. The Campaign on Atmospheric Aerosol Research Network of China: CARE-China. Bull. Am. Meteorol. Soc. 2015, 96, 1137-1155. [CrossRef]

19. Lyapustin, A.; Smirnov, A.; Hoben, B.; Chin, M.; Streets, D.G.; Lu, Z.; Tanre, D. Reduction of aerosol absorption in Beijing since 2007 from MODIS and AERONET. Geophys. Res. Lett. 2011, 38, L10803. [CrossRef]

20. Tao, M.H.; Chen, L.F.; Wang, Z.F.; Tao, J.H.; Che, H.Z.; Wang, X.H.; Wang, Y. Comparison and evaluation of MODIS Collection 6 aerosol data in China. J. Geophys. Res. Atmos. 2015, 120, 6992-7005. [CrossRef]

21. Zhang, Q.; Xin, J.Y.; Yin, Y.; Wang, L.L.; Wang, Y.S. The Variations and Trends of MODIS C5 \& C6 Products' Errors in the Recent Decade over the Background and Urban Areas of North China. Remote Sens. 2016, 8, 754. 
22. Zhu, J.; Xia, X.A.; Wang, J.; Che, H.; Chen, H.; Zhang, J.; Ayoub, M. Evaluation of Aerosol Optical Depth and Aerosol Models from VIIRS Retrieval Algorithms over North China Plain. Remote Sens. 2017, $9,432$. [CrossRef]

23. Eck, T.; Holben, B.; Reid, J.; Mukelabai, M.; Piketh, S.; Torres, O.; Jethva, H.; Hyer, E.; Ward, D.; Dubovik, O. A seasonal trend of single scattering albedo in southern African biomass-burning particles: Implications for satellite products and estimates of emissions for the world's largest biomass-burning source. J. Geophys. Res. Atmos. 2013, 118, 6414-6432. [CrossRef]

24. Ichoku, C.; Chu, D.A.; Mattoo, S.; Kaufman, Y.J.; Remer, L.A.; Tanre, D.; Slutsker, I.; Holben, B.N. A spatio-temporal approach for global validation and analysis of MODIS aerosol products. Geophys. Res. Lett. 2002, 29, 8006. [CrossRef]

25. Levy, R.C.; Mattoo, S.; Munchak, L.A.; Remer, L.A.; Sayer, A.M.; Patadia, F.; Hsu, N.C. The Collection 6 MODIS aerosol products over land and ocean. Atmos. Meas. Tech. 2013, 6, 2989-3034. [CrossRef]

26. Lyapustin, A.; Wang, Y.; Xiong, X.; Meister, G.; Platnick, S.; Levy, R.; Hall, F. Science impact of modis C5 calibration degradation and C6+ improvements. Atmos. Meas. Tech. 2014, 7, 4353-4365. [CrossRef]

27. Levy, R.C.; Remer, L.A.; Dubovik, O. Global aerosol optical properties and application to Moderate Resolution Imaging Spectroradiometer aerosol retrieval over land. J. Geophys. Res. 2007, 112, D13210. [CrossRef]

28. Hsu, N.C.; Jeong, M.J.; Bettenhausen, C.; Sayer, A.M.; Hansell, R.; Seftor, C.S.; Huang, J.; Tsay, S.C. Enhanced Deep Blue aerosol retrieval algorithm: The second generation. J. Geophys. Res. Atmos. 2013, 118, 9296-9315. [CrossRef]

29. Sayer, A.M.; Hsu, N.C.; Bettenhausen, C.; Jeong, M.J. Validation and uncertainty estimates for MODIS Collection 6 “Deep Blue” aerosol data. J. Geophys. Res. Atmos. 2013, 118, 7864-7872. [CrossRef]

30. Tao, M.H.; Chen, L.; Wang, L.; Ma, P.; Tao, J.; Jia, S. A study of urban pollution and haze clouds over northern China during the dusty season based on satellite and surface observations. Atmos. Environ. 2014, 82, 183-192. [CrossRef]

31. Li, J.; Carlson, B.E.; Lacis, A.A. Using Single Scattering Albedo Spectral Curvature to Characterize East Asian Aerosol Mixtures. J. Geophys. Res. Atmos. 2015, 120, 2037-2052. [CrossRef]

32. Lu, Z.; Zhang, Q.; Streets, D.G. Sulfur dioxide and primary carbonaceous aerosol emissions in China and India, 1996-2010. Atmos. Chem. Phys. 2011, 11, 9839-9864. [CrossRef]

33. Chen, Y.; Schleicher, N.; Fricker, M.; Cen, K.; Liu, X.L.; Kaminski, U.; Yu, Y.; Wu, X.F.; Norra, S. Long-term variation of black carbon and PM2.5 in Beijing, China with respect to meteorological conditions and governmental measures. Environ. Pollut. 2016, 212, 269-278. [CrossRef] [PubMed] 